\title{
A New Engineerging Education Model
}

\author{
Jianhua Deng \\ School of Information and Software Engineering, \\ University of Electronic Science and Technology of \\ China \\ Chengdu City, China \\ Jianhua.deng@uestc.edu.cn
}

\author{
Jingye Cai Kun Xiao \\ School of Information and Software Engineering, \\ University of Electronic Science and Technology of \\ China \\ Chengdu City, China \\ \{jycai, xiaokun\}@ uestc.edu.cn
}

\begin{abstract}
Nowadays, the engineers are educated in the traditional way that cannot produce the supply and quality of engineers needed to satisfy the growing demand. Therefore, some new engineering education methods are needed. In this paper, we proposed a new engineering education model to improve the engineering education in order to cultivate students. The graduation students are master the mathematical fundamental, are good at communications and leaderships and have rich engineering experiences.
\end{abstract}

Keywords - engieering education; model; the students; IIS;

\section{INTRODUCTION}

In the last three decades, the economy of China has become the second largest economy in the world within an annual growth rate, $9 \%$. That development is based upon that China has the world's largest industrialized and manufacturing nations [1]. It means that a large number of outstanding engineering talents are demanded. The cultivation of outstanding engineering talents is bound to rely on high-quality engineering education. Therefore, strengthening and emphasis on higher engineering education is of great important to promote science and technology development, economic growth, social progress and national security.

Currently, the engineers are educated in traditional method. Unfortunately, this has not produced the supply and quality of engineers needed to satisfy the growing demand. This demand is rapidly increasing as the economy is growing fast. Further more, traditional education method scants provision for helping students to update their knowledge. Since the engineering field does not distinguish well among different development roles, such as software engineer. Education for software engineers is confounded with education for programmers and other non-engineers.

For the next decade, engineering education should prepare students differently for different roles, infuse a stronger engineering attitude in curricula, help students to face the rapid change, and establish credentials that accurately reflect capability. It is a big challenge that how to satisfy the engineering education demand for the higher education.

In China, the reform of higher education is carrying out to fix this challenge and there is a program was proposed by the Ministry Education of P.R.C called Outstanding Engineer Education Program (OEEP). OEEP aims to cultivate a large number of engineers who have innovative capability and other capabilities to satisfy the demand of economy and social. This program also services for the country to achieve the strategy of new industrialization road and to help to build an innovative country [2]. The OEEP was started on October, 2010 and covers over 340 universities or institutes in China, currently. Therefore, some new engineering education models are proposed in order to develop new methods for cultivation engineers in order to achieve the goal of the OEEP.

In this paper, a new engineering education model will be introduced which is carrying out under the OEEP program. This paper is organized as follows. Some related works will be introduced in section II and in section III a new engineering education model called IIS (Industrialization International - Systemization) will be proposed. Finally, some conclusions will be given in section IV.

\section{CURRENT ENGINEERING EDUCATION MODEL}

In [3], authors defined that the purpose of engineering education is to provide the learning required by students to become successful engineers - technical expertise, social awareness, and a bias toward innovation. They also pointed out that any approaches to improve engineering education must address two questions: (1) What is the full set of knowledge, skills, and attitudes that engineering students should process as they leave the university, and at what level of proficiency? (2). How can we do better at ensuring that students learn these skills? Therefore, they proposed an engineering education system called CDIO which standards for Conceive - Design - Implement - Operate. CDIO collaborators recognize that an engineering education is acquired over a long period and in a variety of institutions, and that educators in all parts of this spectrum can learn from practice elsewhere. The ideal of CDIO is based upon the life cycle of software. The aim of the CDIO is to cultivate the students who should have three capabilities; (1) the first one is that master a deep engineering knowledge of technical fundamentals, (2) the second one is that leading in the creation of new products, processes and systems, (3) the last one is that understanding the importance and strategic impact of research and technological development on society. 
Some engineering education methods are proposed based on the CDIO. [4] proposed a method to improve the vocational education based upon the CDIO engineering education theory. The authors also pointed out the disadvantage of vocational engineering education and explain the reason of that. The authors in [5] defined some technical skills that a software engineer should possess, such as the theoretical foundations of the discipline, the design methods of the discipline and the technology and tools of the discipline. They also pointed that the gap between learning by studying and learning by doing of software engineering is bigger than that of other engineering. The context of the software engineering should be included the mathematical background, the core of computer science and the essentials of the real world.

In this paper, we will introduce an engineering education model in order to reduce the gap between learning by studying and learning by doing.

\section{Proposed Engineering EdUCATION ModeL}

The problems of China's engineering education or the software engineering education are embodied in inadequate investment, old conception and lacking practice. Especially, some students don't have a job after graduated as they do not have any engineering experiences. Therefore, a new model is proposed to improve the students' capabilities by some ways, which is called IIS (Industrialization International - Systemization). The IIS is supported by the OEEP and the Industrialization - International Systemization is a system to achieve the goal of the engineering education.

\section{A. Industrialization}

Industrialization is that the graduation student should be an industrial engineer. It means that the student should have some capabilities as follows:

(1) Master the mathematical fundamental;

(2) Rich industrial engineering experiences;

(3) Excellent communication and leadership skills.

For achieving these goals, a teaching system is designed. Firstly, the students are taught some courses in order to have a solid background in fundamental of mathematics. The traditional continuous mathematics, such as Calculus, and Linear algebra and space analytic geometry, constitutes the general cultural background and educates to rigorous thinking. The no-continuous mathematics, such as discrete mathematics, and digital logic design, provides the essential prerequisites for the computing theory. The students need to study the statistic and probability theory.

Secondly, the core computer science, such as programming $(\mathrm{C} / \mathrm{C}++)$, computer architecture, algorithm and data structures, provides the basic training. In IIS, the core computer science and all the topics taught under "software engineering" should be taught in lab. It means that the students are required to implement the course contexts in computer not only just be taught on the blackboard in classroom but also be required to do some programs. In practice, it is better that the freshmen and sophomores are required coding more than 10,000 lines. On this way, they will have a good skill of coding and have some software engineering experiences.

For rich industrial engineering experience, there are two methods are employed. One method is that the students are taught the popular software or tools in university. The aim is to make sure that the students understand what are using in enterprise. The other way is that the students have to be trained and do internship in enterprise. It can let the students know how to do work as an industrial engineer in a company.

For improving the communications and leadership skills, the students are encouraged to attend into clubs or society. The students are asked to do some presentations in order to improve speech skill.

\section{B. International}

International is that the graduation student should have two capabilities:

(1) They should be good at foreign languages, such as English or French, and have some skills that communication, cooperation or competition with others who have different culture background. For developing these capabilities, all students have to pass the CET 4 examination and are encouraged to pass the CET 6 examination. Some students have opportunities to do internship on aboard. And all students are encouraged to study on aboard.

(2) They should have an open mind to understand what is the most popular technology in currently international industry and what is the development tends. They also need to update knowledge to following the development of industry. Therefore, the students are required to do some projects which are needed to be developed by using the newest industry technologies.

\section{Systemization}

Systemization is that the education process is a system which has two phases. The first phase is the intra education phase and the second one is the external education phase, as shown in Figure 1.

The intra education is that the students are educated in the university which is spent the first 2.5 years. The intra education includes three elements; fundamental courses education, basic professional skills education and basic engineering education. The fundamental courses education is to cultivate the students master the mathematical fundamental and to make them know the essential knowledge which has to be understood as an engineer. The basic professional skills education is to cultivate the students have some skills which have to be master as an engineer. Therefore, there are tens professional optional courses are provided for the students by the university. The 
basic engineering education is to educate the basic engineering experience which usually includes coding and writing documents. Therefore, the students are required to do some programs that are leaded by some teachers who are university staffs or enterprises engineers. The three elements in time is not linear relationship. Generally, the fundamental courses education will be finished in the first year and the basic professional skills education is started at the first half year and will be finished at the end of the first phase. The basic engineering education is spent 1 or 1.5 years.

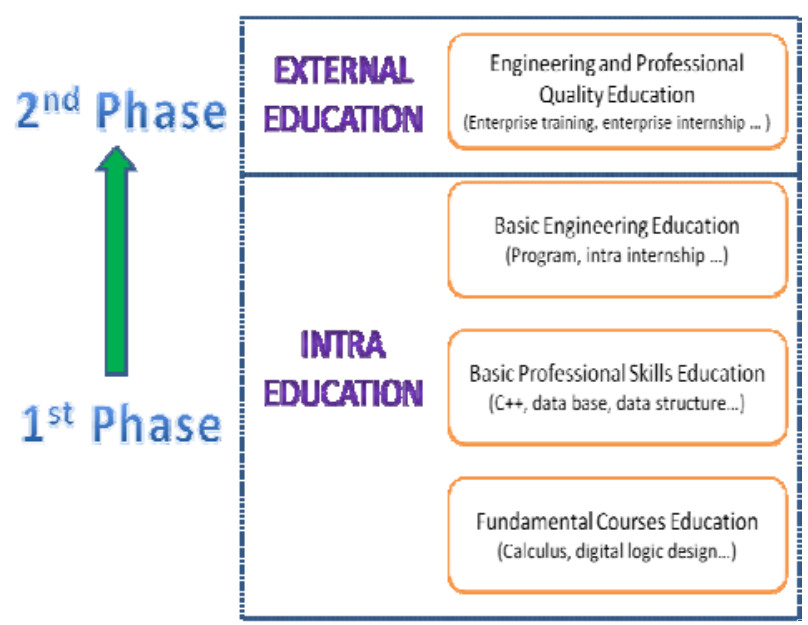

Figure 1. Figure 1: The IIS education model

The external education is that the students are trained by the enterprises or other organizations. In this phase, the students will be strictly trained as an industrial engineer in enterprises where the students can develop more engineering experiences and professional quality. Usually, the external education has three elements; enterprise training, enterprise internship and graduation project. The enterprise training is that the students will be trained by enterprise in order to study and understand some technologies that are currently used in enterprise. And the professional ethics also will be cultivated. The enterprise internship is that the students will be required to attend to do some enterprise programs that are guided by some engineers who have a lot of engineering experiences. The graduation project is that the students are required to finish a project by themselves before education.

\section{CONCLUSION}

In this paper, we proposed a new engineering education model called IIS which has three characters; industrialization, international and systemization. It can overcome the shortcomings of the currently engineering education in order to cultivate outstanding industrial engineers. The model is running well in UESTC and hopefully, it can achieve all aims.

\section{REFERENCES}

[1] W. Zhou, "Engineering education reform needs "Foundation”," Shanghai Education, 2007, 108, pp. 18-20.

[2] http://www.moe.gov.cn/publicfiles/business/htmlfiles/moe/s3860/201 102/115066.html.

[3] E. F. Crauley, S. Ostulnd, J. Malmqvist, D.R. Brodeur, "Rethinking Engineering Education - the CDIO Approach,” Spring, September, 2007, pp. 10.

[4] Q. Xu, D. Xie, "Vocational Engineering Education Model Research,” the $7^{\text {th }}$ International Conference on Computer Science \& Education (ISSCE 2012), pp. 1457 - 1459, July 14 - 17, 2012, Melbourne, Australia.

[5] C. Ghezzi, D. Mandrioli, "The Challenges of Software Education," Proceedings of the 27th international conference on Software engineering (ICSE '05), pp. 637 - 638, 15 - 21 May, 2005, Missouri, USA. 